\title{
Disorders of Sex Development: Lessons to be Learned from Studies of Spina Bifida and Craniofacial Conditions
}

Grayson N. Holmbeck

Loyola University Chicago, gholmbe@luc.edu

\section{L. Aspinall}

Follow this and additional works at: https://ecommons.luc.edu/psychology_facpubs

Part of the Psychology Commons

\section{Recommended Citation}

Holmbeck, Grayson N. and Aspinall, C L.. Disorders of Sex Development: Lessons to be Learned from Studies of Spina Bifida and Craniofacial Conditions. Hormone and Metabolic Research, 47, 5: 380-386, 2015. Retrieved from Loyola eCommons, Psychology: Faculty Publications and Other Works,

http://dx.doi.org/10.1055/s-0035-1545273

This Article is brought to you for free and open access by the Faculty Publications and Other Works by Department at Loyola eCommons. It has been accepted for inclusion in Psychology: Faculty Publications and Other Works by an authorized administrator of Loyola eCommons. For more information, please contact ecommons@luc.edu. c) (i) $(9$

This work is licensed under a Creative Commons Attribution-Noncommercial-No Derivative Works 3.0 License. (c) Georg Thieme Verlag KG, 2015. 


\section{Disorders of Sex Development: Lessons to be Learned from Studies of Spina Bifida and Craniofacial Conditions}

Authors

Affiliations

\section{G. N. Holmbeck ${ }^{1}$, C. L. Aspinall ${ }^{2}$}

${ }^{1}$ Department of Psychology, Loyola University Chicago, Chicago, IL, USA

${ }^{2}$ Seattle Children's Hospital, Craniofacial Center, University of Washington School of Social Work Seattle, WA, USA
Key words

- DSD

- spina bifida

- craniofacial conditions

- research design

- clinical management received 06.10.2014

accepted 15.01.2015

Bibliography DOI http://dx.doi.org/ 10.1055/s-0035-1545273 Published online:

February 26, 2015

Horm Metab Res 2015; 47: 380-386

(c) Georg Thieme Verlag KG Stuttgart · New York ISSN 0018-5043

\section{Correspondence}

\section{G. N. Holmbeck}

Loyola University Chicago Department of Psychology 1032 W. Sheridan Road Chicago

IL 60660

USA

Tel.: + 1/773/5082967

Fax: + 1/773/508 8713

gholmbe@luc.edu

\section{Abstract}

$\nabla$

The purpose of this review is to discuss research methods and clinical management strategies employed with other conditions (i.e., spina bifida and craniofacial conditions) and how these methods and strategies could be applied to youth with disorders of sex development (DSD). The review focuses specifically on the potential over-

\section{What Can be Learned from Studies of Congenital Birth Defects? \\ $\nabla$}

\section{Spina bifida and craniofacial conditions as examples}

The prevalence rate for disorders of sex development (DSD; 1 in 4500) is roughly similar to that found for certain types of congenital birth defects (e.g., the prevalence rate for spina bifida is 3.49 per 10000; [1]). Despite this similarity in prevalence rates, the research literature on psychosocial outcomes, including quality of life, family functioning, individual adjustment, and developmental course, is much less well-developed in the case of DSD. Given this gap in knowledge for DSD, it may be informative to examine research methods in related research areas so as to increase the quality of future research conducted in the area of DSD. The purpose of this paper is to examine research methods and clinical management strategies for 2 congenital conditions that may be particularly informative, namely, spina bifida and craniofacial conditions. In the case of spina bifida, the child is born with a condition that is visible to significant others, potentially stigmatizing, and associated with significant social adjustment issues. With respect to craniofacial conditions, these anomalies are again potentially stigmatizing and also invoke issues related to surgical decision-making that are not unlike those that arise in the case of DSD. More lap between DSD and these other conditions across the following 3 areas: (1) developmentally-oriented theories that underlie the research base for chronic physical conditions; (2) research designs and methodological features that have proved fruitful in these areas; and (3) the potential applicability to DSD of clinical management practices for youth with craniofacial conditions.

\section{What is Spina Bifida?}

$\nabla$

Spina bifida (SB) is a relatively common congenital neural tube defect that is caused by a failed closure of the neural tube during pregnancy. Children with this condition are born with a spinal lesion (which is surgically repaired at birth) and characteristic brain malformations. Associated health complications include weakened or paralyzed lower extremities, urinary and bowel incontinence, hydrocephalus, and learning difficulties. The severity of SB varies in accordance with the spinal lesion level and the presence of neurological complications (e.g., the number of shunt revisions). The clinical symptoms of SB place considerable physical, psychological, and social demands on the individuals and families involved $[2,3]$. Specifically, all of the following 
SB-related stressors likely have a significant and cumulative impact on individual and family functioning: 1 ) the cognitive and neurological features of SB (e.g., executive functioning deficits, attention problems, learning difficulties); 2) the effects of SB on physical development (e.g., precocious puberty, short stature, and obesity are all common in this population [4]); 3 ) the multiple surgical procedures endured by individuals with this condition (e.g., shunt revisions, orthopedic surgeries); 4) the difficulties with bowel and bladder management, as well as the ambulation challenges; 5 ) the characteristic social skills deficits; and 6) individuals' difficulties in mastering developmental milestones (e.g., autonomy development).

\section{What Are Craniofacial Conditions? \\ $\nabla$}

The label "craniofacial conditions" is a broad term used to describe a very wide category of congenital diagnoses that may be isolated to abnormalities of the head and neck, while also including syndromes that may affect other body systems. For example, the most widely known craniofacial conditions are clefts of the lip and/or palate. Some of the more complex craniofacial conditions may be classified clinically by a specific set of characteristics and/or chromosomal patterns. Because of the wide variety, but also the relative rarity of syndromes that involve the skull and other body systems, obtaining birth rates on these individuals is challenging. Reports of the prevalence of cleft conditions typically take into consideration both isolated clefts of the lip or palate as well as those infants born with both a cleft in the lip and palate. Isolated orofacial clefts, with no other birth defects present, are among the most common types of birth defects as defined by the Centers for Disease Control. Specifically, roughly 2650 babies are born in the United States each year with an isolated cleft palate and 4440 infants are born each year with a cleft of the lip and/or palate [5].

In treating craniofacial conditions, there are standards of care that have been set up by consensus, deliberated both nationally and internationally [6]. These standards of care describe not only some of the recommended timelines for care but also identify the constellation of specialized providers that need to be available to provide safe and holistic treatment. One of the hallmarks of multidisciplinary treatment teams is the inclusion of a host of team members, including surgeons, dentists and orthodontists, medical doctors and nurses, speech pathologists, audiologists, ophthalmologists, and psychosocial specialists. The presence of craniofacial conditions interferes with speech, hearing, nutrition, and vision and often includes a risk of intellectual disabilities and the stress of facial differences (for the individual, family, and community). Communication between team members is the key to making certain that treatments do not interfere with any functional aspects of care. Another central component to delivery of care by the team is to make certain to define any questions and concerns voiced by patients and family members, followed up with the provision of timely and adequate support and resources.

\section{Theoretical Basis for Research on Spina Bifida} $\nabla$

A conceptual model or theoretical framework facilitates the development of a program of research (as opposed to a set of unrelated studies) and drives all aspects of the research endeavor
[7]. Influential theories in the field of pediatric psychology tend to share many features: 1 ) a clarity of focus; 2) a developmental emphasis; 3 ) the ability to address limitations of previous research; 4) specification of predictors (i.e., independent variables) and outcomes (i.e., dependent variables), with a clear rationale for each; 5) a clear articulation of links between predictors and outcomes (that sometimes involves specification of mediational and moderational pathways) with accompanying testable hypotheses; and 6) clear implications for interventions. There are several theoretical models that identify multiple factors and contexts that directly and indirectly influence child development, psychosocial adjustment, and family functioning in children with chronic health conditions (e.g., [8,9]). Here, we provide one example of such a theoretical model, namely, a bioneuropsychosocial model of psychological adjustment in youth and emerging adults with spina bifida ( $\bullet$ Fig. 1). As illustrated in $\odot$ Fig. 1, the adjustment of individuals with SB is likely determined by the interacting influences of multiple biological, neuropsychological, and social factors. Although not included in the model, contextual variables such as social class, the cultural and religious background of the family, ethnicity, family structure, gender, and neighborhood/community factors can all play roles in modifying associations among the constructs included in $\odot$ Fig. 1. All of the constructs included in $\odot$ Fig. 1 are particularly relevant for youth and young adults with spina bifda; thus, with models such as these, it is critical to select constructs that are salient for the condition under investigation. Moreover, all of

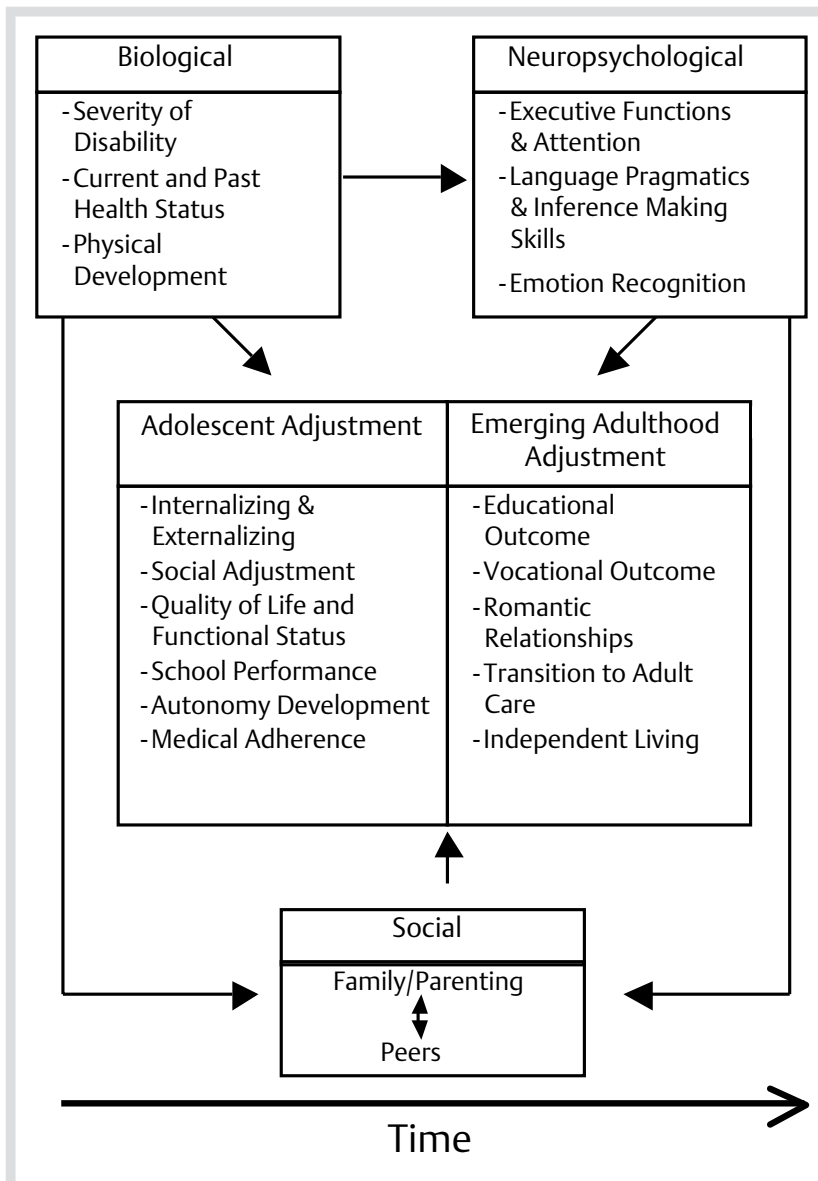

Fig. 1 Bio-neuropsychosocial model of psychological adjustment in children, adolescents, and emerging adults with spina bifida. From ref. [45]. Copyright 2010 by Wiley-Blackwell. Reprinted with permission. 
these factors likely have causal relations with each other, with each evolving and changing over time. Indeed, "time" is included in the model to indicate that associations among the processes evolve with development and over time. As such, the model is inherently "developmental" with different constructs becoming relevant at different developmental stages (e.g., pubertal development during early adolescence).

Finally, each construct within $\bullet$ Fig. 1 can be considered a second-order domain with multiple first-order sub-domains. For example, the family domain includes multiple sub-domains, such as the following: parental adjustment, parenting behaviors, parenting satisfaction, parenting stress, family system-level constructs (e.g., conflict, affect, cohesion), family burden, family problem-solving abilities, family coping, family management of the medical condition and adherence, family life events, and marital functioning. These sub-domains may have an impact on each other, in addition to having an impact on the individual's level of adjustment. Moreover, the manner in which spina bifida has an impact on a family system can vary within a family system over time. For example, a family may function adaptively while their child with spina bifida is in grade school, but have difficulty adjusting when the same child transitions into adolescence.

With respect to DSD, it will be important for researchers to develop a theoretical model such as this before embarking on extensive longitudinal research. Care should be taken to create a model that highlights constructs that are particularly salient for DSD. Once the model is established, such a model will guide future research endeavors by isolating variables of interest and providing a framework for the testing of complex hypotheses and models.

\section{Research Designs in Studies of Other Conditions \\ $\nabla$}

In this section, we review research design strategies that will likely be useful to those who study psychosocial outcomes in youth with DSD.

\section{Developmental Perspective on Research: The Utility of Longitudinal Designs}

Longitudinal studies permit examination of changes in healthrelated behaviors and processes over time. Such designs can be retrospective or prospective, with the latter having clear advantages over the former [10]. Prospective longitudinal investigations of children with chronic physical conditions may be particularly informative when change is examined during critical developmental periods or transition points (e.g., early childhood, the transition to school, the early adolescent transition, the transition to adulthood). At the most complex level of analysis, the task for the researcher is to understand a chronic condition that is changing over time in an individual who is also changing, developing, and maturing over time. The advantages of longitudinal designs include the following [11]: 1) adjustment can be studied prospectively, including specification of the onset, duration, termination, and outcomes of adjustment trajectories; 2) the prediction of future outcomes from earlier factors; 3 ) the ability to establish a typology of developmental sequences and trajectories; 4) the study of how at-risk populations negotiate and are affected by critical developmental periods; and 5) the study of prevention interventions and the maintenance of change. Thus, longitudinal methodology and a developmental psychopathology perspective can be integral to the advancement of knowledge regarding any chronic physical condition, including DSD.

\section{A Developmental Psychopathology Perspective: Resilience and Multifinality}

The field of "developmental psychopathology" provides several key concepts applicable to longitudinal research in pediatric psychology (e.g., developmental trajectories, resilience, risk and protective processes, continuity-discontinuity, multifinality, equifinality [12]). For example, research on developmental trajectories has elucidated developmental processes leading to eventual adjustment difficulties. In adolescents with type 1 diabetes, for example, children who are granted excessive levels of self-care autonomy during the early adolescent period are on a developmental trajectory that is more likely to result in less favorable treatment adherence rates and higher hospitalization rates [13]. Moreover, the concept of multifinality is clearly relevant to the study of DSD; specifically, multifinality is said to occur if 2 children with the same condition of the same severity exhibit different psychosocial outcomes. The developmental psychopathologist would be interested in isolating the factors that precede or account for such differential outcomes.

Several longitudinal studies have focused on long-term adjustment and developmental outcomes in pediatric populations, including cancer, spina bifida, traumatic brain injury, and juvenile rheumatoid arthritis (e.g., [14-16]). These studies have revealed that some illness groups adjust relatively well over the long-term, whereas others may be at risk for psychosocial deficits. Longitudinal methodology also enables pediatric psychologists to understand the complex interplay between development and illness status. For example, we know that decreased family cohesion and increased family conflict in response to pubertal development during adolescence are considered normative developmental processes in typically developing youth. Families of adolescents with spina bifida, however, do not appear to experience these changes in family relations during adolescence, possibly representing a lack of familial responsiveness to physical developmental changes in this population [17].

Simply put, longitudinal research with pediatric populations sheds light on similarities and differences between the "normative" development of typically-developing children and the development of children affected by chronic illness. Also, as developmental expectations change over time (on the part of children, parents, and health professionals), new medical and psychosocial challenges may emerge or become more salient. For example, autonomy development and medical adherence issues are important constructs in individuals with chronic conditions, and particularly during adolescence and young adulthood.

\section{Considerations in Designing Longitudinal Research with Pediatric Populations}

Although there are a number of general designed-related issues and challenges to consider when developing longitudinal research protocols (e.g., financial cost, participant attrition, the degree to which the same measures can be used across different age groups), we focus here on issues that are particularly relevant to the study of children with chronic physical conditions. In this section, we discuss cohort effects, the number of data collection points, measurement issues, and attrition and sample size issues in studies of pediatric populations. 
With respect to cohort effects, medical treatments that are applied to children with chronic conditions are continually being upgraded. Thus, different cohorts of research participants may have developed along different trajectories because of the type of standard of care that was in place for each cohort. To manage this particular barrier to longitudinal research, cohortsequential research designs are useful. With such designs, multiple cohorts are followed over time, thus permitting examination of cohort effects and whether longitudinal findings vary as a function of the type of care available for particular cohorts at given times.

Although 2 data points may provide information about increases or decreases over time, the basic rule of thumb is that more data collections are preferred $[18,19]$. Moreover, since developmental change is continuous, 2 points provide little information regarding the patterns of change. For statistical reasons, growth models that include linear or quadratic effects are best estimated with 3 or more data points. Also, if one seeks to test a mediational model, longitudinal designs can provide the data necessary to test such models [20-22].

With respect to multiple waves of data collection, an important measurement issue involves determining which respondents are the most qualified reporters of constructs of interest and whether such respondents should vary with the age of the child. Although this issue is relevant to all longitudinal research, the issue is often more complex for some variables in studies of pediatric populations. With respect to medical adherence, for example, parents may be the most appropriate reporters for preadolescents. But, with age, children may be able to contribute to the assessment of adherence. As such, parents and children can be interviewed as a dyad. On the other hand, it is also important to note that growth analyses require that there be no change in the measures over time. Thus, if one seeks to conduct such analyses, the researcher needs to determine whether the chosen measures can be administered repeatedly over the time span of the study.

Attrition is also a factor in longitudinal research that takes on added salience in studies of pediatric populations. For example, some children may become too ill to participate or, at the other end of the severity continuum, some children with mild forms of a condition may no longer view themselves as having a chronic illness and may prefer to withdraw from the study. To reduce the degree of attrition in our studies of spina bifida, we conduct our assessments during home visits (i. e., we make no travel demands on the families). Statistically speaking, attrition in studies of pediatric populations is probably more likely to be nonrandom than in studies of typically-developing children. Relatedly, attrition is also a particularly critical issue in the field of pediatric psychology because initial sample sizes are not likely to be large, due to low base rates in the population. Accordingly, longitudinal studies in pediatric psychology are almost always underpowered. To address this issue, many have suggested that multi-site studies be conducted. However, potential difficulties can arise when pooling data across a heterogeneous set of institutions.

\section{Testing Complex Models: Moderation and Mediation}

Variables that have an impact on the association between 2 or more other variables are typically referred to as moderator variables $[21,22]$. A moderator is a variable that influences the strength or the direction of a relationship between a predictor variable and a criterion variable ( $\bullet \mathbf{F i g} . \mathbf{2 a}$ ). Suppose a researcher

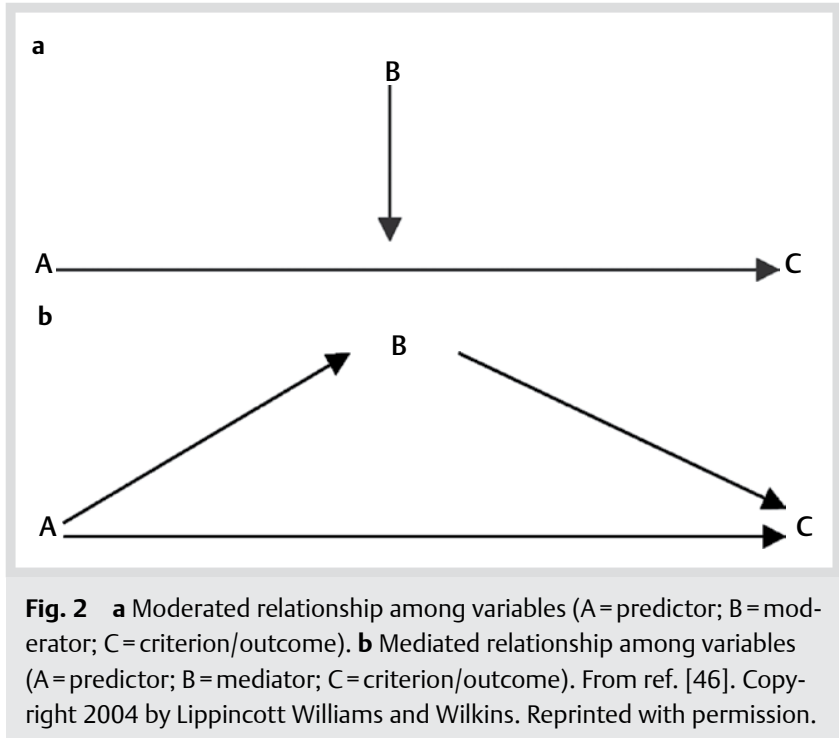

is interested in examining whether the relationship between familial stress and child adjustment to a chronic condition depends on the level of uncertainty that characterizes a child's condition. That is, a significant association between stress and adjustment may emerge only when there is considerable uncertainty regarding the child's illness status. By testing level of uncertainty as a moderator of the relationship between stress and outcome, the researcher can specify the conditions under which family stress predicts child adjustment.

A mechanism that explains why 2 or more variables are associated is referred to as a mediator variable. Often a mediator variable is conceptualized as the mechanism through which one variable (i.e., the predictor) influences another variable (i.e., the criterion [21-23]; see $\odot$ Fig. 2b). Suppose that a researcher finds that parental intrusive behavior is negatively associated with child adherence to a medical regimen. Given these findings, a researcher could explore whether a third variable (e.g., child independence) might account for or explain the relationship between these variables. In this case, it might be hypothesized that parental intrusiveness would impact negatively on level of child independence, which, in turn, would contribute to poor medical adherence. Although the logic underlying meditational models is often straightforward, a host of rather complex mediational models have been proposed (e.g., see Rose et al.'s discussion of mediated moderation and moderated mediation [24]).

\section{Observational Research Designs}

Most research in pediatric psychology employs observational research designs and methods. Kazdin [25] and Mann [26] reviewed different types of designs that fall in this category, including 1) cohort studies, and 2) case control studies. Cohort studies are used to examine variables that precede the development of some outcome. With such a design, one might examine a cohort of individuals over time to determine what variables are associated with the occurrence of an adjustment-related outcome, such as peer rejection or a depressive disorder. The advantage of cohort designs is that they allow one to establish a time line that precedes the outcome of interest, with predictors that are not biased by the occurrence of the outcome [25]. In a case control study, the investigator identifies samples that do or do not exhibit the outcome of interest (e.g., peer rejection, 
depression). An important difference between case control studies and cohort studies is that cohort studies follow a group of participants who have not yet exhibited the outcome of interest to determine who will and who will not exhibit the outcome of interest $[25,26]$. In case control studies, the investigator compares those who already exhibit the outcome with those who do not. The most common case control design is cross-sectional, where one compares 2 groups on variables of interest and these variables are usually assessed retrospectively.

\section{Challenges when conducting research with pediatric populations}

Several research issues pertain specifically to the study of pediatric populations. First, it is important to determine the setting in which the data will be collected. Many pediatric populations regularly attend hospital clinics; thus, clinic based data collections may be a relatively efficient strategy. On the other hand, there are certain drawbacks to this strategy: 1) children and/or parents may be particularly stressed during clinic visits; 2) children are often accompanied by only one caregiver, making it difficult to assess all family members (especially fathers); and 3) clinic settings are busy environments which may be distracting to research participants and can make it difficult to complete an entire research protocol. An additional concern related to conducting research in clinical settings is that this type of setting may "prime" respondents in certain ways that may influence their responses. Referred to as the "focusing illusion," this phenomenon occurs when a respondent is directed to focus on a specific aspect of their functioning (e.g., medical status); such a focus will then enhance associations between this variable and other outcomes of interest, since the priming will presumably have an impact on responses to all measures [27]. In the case of clinic-based research, the setting may prime participants to respond to all measures with their medical status as cognitively "front and center". For this reason, we counterbalance all measures and observational tasks so that measures that are administered earlier in the protocol do not systematically prime the respondents in relation to later measures [28].

Decisions also need to be made concerning the nature of the data to be collected. For instance, one may ask: What sources or informants will provide the data? What methods will be used to collect the data? Answers to these questions are critical because they will impact on one's ability to rule out alternative explanations for one's findings. Moreover, one may not be able to assess all constructs of interest from the perspective of all informants because such a comprehensive assessment will produce a high level of burden for the research participants. Also, these data collections are expensive; thus, the assessments need to be conducted as efficiently as possible with the most valid instruments available. When conducting a longitudinal study, it is critical that one attend to issues of attrition and retention. Several strategies are available to reduce attrition. First, it is helpful to foster the participants' commitment to the study. This can be accomplished by sending project newsletters to participants. Second, it is important to develop a tracking system to keep participants' contact information current. Third, at each data collection point, it is important to gather contact information for individuals who are likely to know the whereabouts of a given participant in the future. Finally, if one has funds to compensate participants for their work, one can increase the compensation at each data collection point, with a "bonus" provided to those who complete all data collections (although one should avoid making such inducements coercive).

\section{Applicability to DSD of Lessons Learned from the Clinical Management of Other Conditions}

$\nabla$

When a child is born with a congenital condition, the clinical care of patients and families must include attention to a wide variety of complex intellectual and emotional developmental concerns. For example, in cases involving DSD, spina bifida, and craniofacial conditions, attention to these concerns will be preparatory (at discovery prior to delivery [29]), reactive (when a condition is discovered at birth), and then must be adjusted over time with the patient, family/community, and the medical team. Such attention involves focusing on evolving multi-faceted psychological issues [30]).

Most congenital conditions involve the presence of both visible and hidden characteristics. While not all visible differences will be seen by all those who come in contact with a child, the fact that they are known to the patient, family, and community can affect adjustment issues. In the case of craniofacial and spina bifida patients, there will be public awareness of some of the visible characteristics. An older child with spina bifida who has mobility restrictions will be seen by all as "different," as will a child born with cleft of the lip (even after surgery to close the initial opening, since a scar remains). In the case of a "hidden" defect, such as a genital difference or hydrocephalus, there is a dramatic internal struggle about the "difference" that is often felt by adults (particularly parents) that is shame-based and often laden with feelings of guilt, blame, fear, sadness, and responsibility [31-33]. Thus, although the public may not observe all differences, there is still a significant emotional impact on the adults involved and these strong emotions will indirectly guide the treatment planning.

The strong feelings of shame and guilt that caregivers feel at the time of discovery are often described vividly as grief-like and as difficult to process (whether as individuals, couples, families, or in the larger community). These strong reactions are often observed by medical providers both in hospitals and clinics; such professionals are activated to reduce the psychological suffering that is exhibited by parents/caregivers. This intense grief then morphs into fear of the unknown with respect to how this condition will affect how the child's body works (e.g., are there any biologic threats to survival?) and how the child will be perceived by others (e.g., will they be rejected and suffer psychologically from the prejudice and taunting of others)? [34,35]. Given these emotional reactions, it is critical that psychosocial providers be present and involved, beginning with the moment of discovery. Such trained providers can negotiate parental grief and fear and help the parent to view the child as connected to, but separate from, their own feelings. At the same time, the psychosocial provider must help the medical team to understand the emotional status of the family and begin the process of helping the family communicate with the medical/surgical treatment team. Such direction from the providers will prevent the parents' fear and shame to be the driving force behind decisions involving surgery $[36,37]$. An excessive feeling of urgency on the part of parents may lead to a rush to the operating room for body-changing surgery (that also involves additional risks). It may be that such surgery can wait, given that the surgery could 
make a change that "burns a bridge" for that child's body that cannot be rebuilt or reversed. The family can benefit if the treatment team seeks a better understanding of the patient and family's definition of the condition and if we let the family and child tell us when and if there is a "problem" [38].

To facilitate an adaptive decision-making process, providers will spend time examining clinically the "meaning" assigned to the diagnosis by the family. When the patient is an infant, the caregiver(s) are the focus of the interview. But, even at this early stage, counseling is provided to help the family allow some time to pass (when medically safe) so that the child can participate in the decision-making. If treatment is determined to be necessary, barriers to getting through the treatment must be identified and remedied when possible. It is also critical to discuss any cultural contexts that need to be understood and integrated into how care is delivered [39].

Research methodologies mentioned earlier will help us all to look more objectively at whether or not the treatments, surgeries, and counseling that are done truly help to improve the quality of life of patients and other family members over time. In the area of craniofacial care, longitudinal cohort studies are underway to examine youth with diagnoses such as single suture synostosis [40]) and qualitative research is ongoing to determine if the clinical work done to support children and families is "on track" $[33,41]$. This research will examine whether the current standard of care (i.e., having social workers meet all families and children after birth and following them over 20 years) is useful to families.

As all stakeholders become better acquainted with one another and boundaries and communication processes are established, we will all be in a better place to work on making shared and informed decisions - with the young patient's quality of life squarely in our sights. Along the way, families will discover other resources that will become useful for emotional support and validation, including support groups (in person and online), parent advisory committees, and advocacy groups [42,43]. We need to help families' access such support and resources, but we also need to insist that such support be evidence-based and integrates well with support provided by medical professionals [44]. More generally, it is the combination of high quality, evidence-based care combined with objective, well-constructed research that will put us in the best possible position to facilitate an acceptable quality of life in children with chronic physical conditions, including DSD.

\section{Acknowledgements \\ $\nabla$}

Completion of this paper was supported by research grants to Holmbeck from the Eunice Kennedy Shriver National Institute of Child Health and Human Development (R01-HD048629) and the March of Dimes (12-FY13-271).

\section{Conflict of Interest}

$\nabla$

The authors declare that they have no conflicts of interest in the authorship or publication of this contribution.

\section{References}

$1 C D C$. Data and statistics: Neural tube defect ascertainment project. 2014;September 30. Retrieved from http://www.cdc.gov/ncbddd/ spinabifida/data.html

2 Holmbeck GN, Westhoven V, Phillips WS, Bowers R, Gruse C, Nikolopoulos T, Totura CW, Davison K. A multimethod, multi-informant, and multidimensional perspective on psychosocial adjustment in preadolescents with spina bifida. J Consul Clin Psych 2003; 71: 782-796

3 Holmbeck GN, DeLucia C, Essner B, Kelly L, Zebracki K, Friedman D, Jandasek $B$. Trajectories of psychosocial adjustment in adolescents with spina bifida: A six-year four-wave longitudinal follow-up. J Consul Clin Psych 2010; 78: 511-525

4 Dosa NP, Foley JT, Eckrich M, Woodall-Ruff D, Liptak GS. Obesity across the lifespan among persons with spina bifida. Disabil Rehabil 2009; 31: 914-920

5 CDC. Data and Statistics: Facts about Cleft Lip and Cleft Palate. 2014; October 2. Retrieved from http://www.cdc.gov/ncbddd/birthdefects/ CleftLip.html

6 American Cleft Palate-Craniofacial Association. Parameters for the Evaluation and Treatment of Patients with Cleft Lip/Palate or Other Craniofacial Anomalies. Cleft Pal Cran J 1993; 30 (Suppl): S1-S16

7 Riekert KA, Drotar D. Adherence to medical treatment in pediatric chronic illness: Critical issues and answered questions. In: Drotar D (ed.). Promoting adherence to medical treatment in chronic childhood illness. Mahwah, NJ: Erlbaum, 2000; 3-32

8 Kazak AE, Rourke MT, Navasaria N. Families and other systems in pediatric psychology. In: Roberts MC, Steele RG (eds.). Handbook of pediatric psychology. $4^{\text {th }}$ ed. New York: Guilford Press, 2009; 656-671

9 Wallander JL, Thompson RJ, Alriksson-Schmidt A. Psychosocial adjustment of children with chronic physical conditions. In: Roberts MC, Steele RG (eds.). Handbook of pediatric psychology. $3^{\text {rd }}$ ed. New York: Guilford Press, 2003; 141-158

10 Holmbeck GN, Bruno LF, Jandasek B. Longitudinal research in pediatric psychology: An introduction to the special issue. J Ped Psych 2006: 31: 995-1001

11 Loeber R, Farrington DP. Problems and solutions in longitudinal and experimental treatment studies of child psychopathology and delinquency. J Consul Clin Psych 1994; 62: 887-900

12 Cicchetti D, Rogosch FA. A developmental psychopathology perspective on adolescence. J Consult Clin Psych 2002; 70: 6-20

13 Wysocki T, Taylor A, Hough BS, Linscheid TR, Yeates KO, Naglieri JA. Deviation from developmentally appropriate self-care autonomy: Associations with diabetes outcomes. Diabetes Care 1996; 19: 119-125

14 Friedman D, Holmbeck GN, Jandasek B, Zukerman J, Abad M. Parent functioning in families of preadolescents with spina bifida: Longitudinal implications for child adjustment. J Fam Psych 2004; 18: 609-619

15 Reiter-Purtill J, Gerhardt CA, Vannatta K, Passo MH, Noll RB. A controlled longitudinal study of the social functioning of children with juvenile rheumatoid arthritis. J Ped Psych 2003; 28: 17-28

16 Wade SL, Taylor HG, Drotar D, Stancin T, Yeates KO, Minich NM. Interpersonal stressors and resources as predictors of parental adaptation following pediatric traumatic injury. J Consult Clin Psych 2004; 72 : 776-784

17 Coakley RM, Holmbeck GN, Friedman D, Greenley RN, Thill AW. A longitudinal study of pubertal timing, parent-child conflict, and cohesion in families of young adolescents with spina bifida. J Ped Psych 2002; 27: 461-473

18 Singer JD, Willett JB. Applied longitudinal data analysis: Modeling change and event occurrence. Oxford, UK: Oxford University Press, 2003

19 Willett JB, Singer JD, Martin NC. The design and analysis of longitudinal studies of development and psychopathology in context: Statistical models and methodological recommendations. Devel Psychopath 1998; 10: 395-426

20 Cole DA, Maxwell SE. Testing mediational models with longitudinal data: Questions and tips in the use of structural equation modeling. J Abn Psych 2003; 112: 558-577

21 Holmbeck GN. Toward terminological, conceptual, and statistical clarity in the study of mediators and moderators: Examples from the child-clinical and pediatric psychology literatures. J Consult Clin Psych 1997; 65: 599-610

22 Holmbeck GN. Post-hoc probing of significant moderational and mediational effects in studies of pediatric populations. J Ped Psych 2002; 27: 87-96

23 MacKinnon DP. Introduction to statistical mediation analysis. New York: Erlbaum, 2008 
24 Rose B, Holmbeck GN, Coakley RM, Franks L. Mediator and moderator effects in developmental and behavioral pediatric research. J Develop Behav Pediatr 2004; 25: 1-10

25 Kazdin AE. Research design in clinical psychology. $4^{\text {th }}$ ed. Boston: Allyn and Bacon, 2003

26 Mann CJ. Observational research methods. Research design II: Cohort, cross-sectional, and case control studies. Emerg Med J 2003; 20: 54-60

27 Schkade DA, Kahneman D. Does living in California make people happy? A focusing illusion in judgments of life satisfaction. Psych Sci 1998; 9: 340-346

28 Smith DM, Schwartz N, Roberts TR, Ubel PA. Why are you calling me? How study introductions change response patterns. Qual Life Res 2006; 15: 621-630

29 Aspinall CA. Dealing with the prenatal diagnosis of clefting: A parent's perspective. Cleft Pal Cran J 2002; 39: 183-187

30 Endriga MC, Kapp-Simon KA. Psychosocial issues in craniofacial care: State of the art. Cleft Pal Cran J 1999; 36: 3-11

31 Hunfeld JA, Tempels A, Passchier J, Hazebroek FW, Tibboel D. Brief report: Parental burden and grief one year after the birth of a child with a congenital anomaly. J Ped Psychiatr 1999; 24: 515-520

32 Barnett D, Clements M, Kaplan-Estrin M, McCaskill J, Hill-Hunt K, Butler CM, Schran J, Janisse HC. J Fam Psychol 2006; 20: 100-107

33 Patrick DL, Topolski TD, Edwards TC, Aspinall CL, Kapp-Simon KA, Rumsey NJ, Strauss RP, Thomas CR. Measuring the Quality of Life of Youth With Facial Differences. Cleft Pal Cran J 2007; 44: 538-547

34 Thomasgard M, Metz WP. The vulnerable child syndrome revisited. Dev and Behavioral Peds 1995; 16: 47-53

35 Endriga MC, Jordan JR, Speltz ML. Emotion self-regulation in preschool - aged children with and without orofacial clefts. Dev Behav Peds 2003; 24: 336-344

36 Marsh JL. To cut or not to cut? A surgeon's perspective on surgically shaping children. In: Parens E (ed.). Surgically Shaping Children: Technology, Ethics and the Pursuit of Nomality. New York: Johns Hopkins Press, 2006; 113-124
37 Murray TH. Research on children and the scope of responsible parenthood. In: Murray TH. The Worth of the Child. Los Angeles: University of California Press, 1996; 70-95

38 American Academy of Pediatrics. Patient and family centered care and the pediatrician's role. Pediatrics 2012; 129: 394-404

39 Aspinall C. Social Work: Assessing family issues and burdens of care. In: Moller K, Glazer L (eds.). Cleft lip and palate: Interdisciplinary issues and treatment (For clinicians by clinicians). Austin: Pro-Ed, 2008; 39-53

40 Cloonan YK, Collett B, Speltz ML, Anderka M, Werler MM. Psychosocial outcomes in children with and without non-syndromic craniosynostosis: Findings from two studies. Cleft Pal Cran J 2013; 50: 406-413

41 Edwards TC, Patrick DL, Topolski TD, Aspinall CL, Mouradian WM, Speltz $M L$. Approaches to craniofacial specific quality of life assessments in adolescents. Cleft Pal Cran J 2005; 42: 19-24

42 Kratz L, Uding N, Trahms CM, Villareale N, Kieckherer GM. Managing childhood illness: Parent perspectives and implications for parentprovider relationships. Fam Systems and Hlth 2009; 27: 303-313

43 Williams $L$. The many roles of families in family-centered care: Part III. Ped Nursing 2007; 33: 144-146

44 Baratz $A B$, Sharp MK, Sandberg DE. Disorders of sex development peer support. In: Hiort O, Ahmed SF (eds.). Understanding differences and disorders of sex development (DSD). Basel: Karger, 2014; 99-112

45 Holmbeck GN, Devine KA. Psychological and family functioning in spina bifida. Develop Disabil 2010; 16: 40-46

46 Rose BM, Holmbeck GN, Coakley RM, Franks EA. Mediator and moderator effects in developmental and behavioral pediatric research. Devel Beh Ped 2004; 25: 1-10 